\title{
Differential gene expression analysis of in vitro duck hepatitis B virus infected primary duck hepatocyte cultures
}

\author{
Sajith Nair, Devaki S Arathy, Aneesh Issac and Easwaran Sreekumar
}

\begin{abstract}
Background: The human hepatitis B virus (HBV), a member of the hepadna viridae, causes acute or chronic hepatitis B, and hepatocellular carcinoma (HCC). The duck hepatitis B virus (DHBV) infection, a dependable and reproducible model for hepadna viral studies, does not result in HCC unlike chronic HBV infection. Information on differential gene expression in DHBV infection might help to compare corresponding changes during HBV infection, and to delineate the reasons for this difference.

Findings: A subtractive hybridization cDNA library screening of in vitro DHBV infected, cultured primary duck hepatocytes (PDH) identified cDNAs of 42 up-regulated and 36 down-regulated genes coding for proteins associated with signal transduction, cellular respiration, transcription, translation, ubiquitin/proteasome pathway, apoptosis, and membrane and cytoskeletal organization. Those coding for both novel as well as previously reported proteins in HBV/DHBV infection were present in the library. An inverse modulation of the cDNAs of ten proteins, reported to play role in human HCC, such as that of Y-box binding protein1, Platelet-activating factor acetylhydrolase isoform 1B, ribosomal protein L35a, Ferritin, $\alpha$-enolase, Acid $\alpha$-glucosidase and Caspase 3, copper-zinc superoxide dismutase (CuZnSOD), Filamin and Pyruvate dehydrogenase, was also observed in this in vitro study.

Conclusions: The present study identified cDNAs of a number of genes that are differentially modulated in in vitro DHBV infection of primary duck hepatocytes. Further correlation of this differential gene expression in in vivo infection models would be valuable to understand the little known aspects of the hepadnavirus biology.
\end{abstract}

\section{Introduction}

The human hepatitis B virus (HBV) and the duck hepatitis $B$ virus (DHBV), which are members of the same virus family, hepadnaviridae, share several features in common [1]. Unavailability of primary animal models susceptible to HBV infection, and inefficiency and unreliability of the infection process in in vitro systems [2] are major limitations in HBV research which restrain the study of this major human pathogen. But the establishment of the animal model with domestic duck employing the DHBV has helped greatly to overcome the shortcomings in HBV research $[1,3]$. However, this model has its own limitations as revealed by the differences in the clinical manifestations of the disease in humans and birds infected by these viruses. This mainly pertains to the chronicity in

\footnotetext{
* Correspondence: esreekumar@rgcb.res.in

Molecular Virology Laboratory, Rajiv Gandhi Centre for Biotechnology (RGCB), Thycaud P.O., Thiruvananthapuram-695014, Kerala, India
}

DHBV infection without liver injury/hepatocellular carcinoma (HCC)/cirrhosis; spontaneous elimination of infection in adult ducks; and at the molecular level, the expression of only a cryptic X-protein [4]. A major lacuna in HBV biology is the lack of sufficient information on the molecular mechanisms involved in the development of HCC in chronic HBV patients, which has become a major medical challenge [5].

A few studies have been performed comparing the gene expression in HBV positive HCC and non-cancerous liver [6] and viral and non-viral HCC [7] in patient samples. However, no study has focused to identify the differential gene expression in infection with DHBV either in vivo or in vitro to facilitate a comparative analysis. A recent in vitro study has addressed the proteomic changes during DHBV infection, which has brought to light a number of genes that are involved in the infection process [8]. However, a purely proteome based approach might not reveal

C Biomed Central

(c) 2011 Nair et al; licensee BioMed Central Ltd. This is an Open Access article distributed under the terms of the Creative Commons Attribution License (http://creativecommons.org/licenses/by/2.0), which permits unrestricted use, distribution, and reproduction in any medium, provided the original work is properly cited. 
changes in the expression levels of many of the low abundant proteins due to technical limitations, which needs to be complemented by mRNA/cDNA differential expression based approaches. In this context, we carried out a subtractive hybridization cDNA library construction and screening to identify the differential gene expression during DHBV infection in primary duck hepatocytes (PDH) in culture. The protocol we followed identified 42 upregulated and 36 down-regulated genes in DHBV infected $\mathrm{PDH}$ in culture.

\section{Methods}

Primary duck hepatocytes (PDH) were isolated from 27day old embryonated, un-hatched, duck eggs free of duck hepatitis B virus (DHBV) infection as previously described [9] and maintained at $5 \times 10^{6}$ cells $/ \mathrm{ml}$ in DMEM+F12 (Sigma) and 5\% FBS supplemented with glucose $(0.5 \mathrm{gm} / \mathrm{l})$, dexamethasone $\left(10^{-5} \mathrm{M}\right)$ and insulin $(1 \mu \mathrm{g} / \mathrm{ml})$ (all from Sigma) at $37^{\circ} \mathrm{C}$ in a $5 \% \mathrm{CO}_{2}$ atmosphere. DHBV stock was concentrated from LMH-D2 cell culture supernatant, a chicken hepatoma cell line that constitutively replicate DHBV, (a kind gift from Dr. William S Mason, Fox Chase Cancer Centre, California), by precipitation with $10 \%$ polyethylene glycol 8000 (USB, USA) [10]. The pellet was re-suspended in $\mathrm{DMEM}+\mathrm{F} 12$ medium and this concentrated virus was used to infect PDH at an MOI of $10^{3}$ genome equivalents per hepatocyte, as previously described [11] in presence of 1\% DMSO (Sigma). DHBV infection was confirmed by PCR on the DNA obtained from the culture supernatant using DHBV specific primers P1F and D2R (Additional File 1, Table 1).

$2 \mu \mathrm{g}$ of polyA RNA each from DHBV infected and uninfected PDH on zero and $4^{\text {th }}$ day of infection was isolated using PolyATract mRNA isolation system-III (Promega, USA) and was used to construct forward and reverse subtracted cDNA libraries using Clontech PCR-Select cDNA subtraction kit (Clontech, USA), as per kit protocols. PCR amplification of a house-keeping gene GAPDH (Additional File 1, Table 1) from subtracted and un-subtracted samples was used for confirmation of the subtraction efficiency. The subtracted cDNAs were ligated with the pGEM-T (Easy) vector (Promega), competent JM109 Escherichia coli cells (Promega) were transformed and plasmids were isolated following standard molecular biology protocols to obtain 137 forward and 148 reverse subtracted clones.

Macroarrays of these plasmids were generated by vacuum transferring $100 \mathrm{ng}$ each of the denatured clone plasmid in duplicate spots onto nylon membranes (Hybond-N+, Amersham Biosciences UK) using a dotblot apparatus (Bio-Dot, Bio-Rad). The arrays were hybridized with $\alpha^{32}$ P labelled forward and reverse subtracted cDNA mixtures as radioactive probes in a reverse-northern procedure. The probes were radiolabelled in a $50 \mu \mathrm{l}$ PCR reaction using $\left[\alpha^{32} \mathrm{P}\right]$-dCTP, dATP, dGTP, dTTP (0.2 mM each) and unlabelled $\mathrm{dCTP}(0.02 \mathrm{mM})$ using the nested PCR primers 1 and 2R (10 $\mu \mathrm{M}$ each) (Additional File 1, Table 1) and the Advantage 2 polymerase mix (Clontech). The adaptor regions common to both the probe and library clones were removed by digestion with RsaI restriction enzyme (NEB). The arrays were individually hybridized with both forward and reverse radio-labelled probes. Subsequent to a pre-hybridization of the membrane for 30 min in the hybridization solution(10\% Polyethylene glycol, 1.5 $\times$ SSPE and 7\% sodium dodecyl sulphate), heat denatured probe solution containing $100 \mu \mathrm{l}$ of RsaI digested radio-labelled probe, $250 \mu \mathrm{l}$ of $10 \mathrm{mg} / \mathrm{ml} \mathrm{Her-}$ ring sperm DNA(Promega) and $100 \mu$ of $0.2 \mathrm{~N} \mathrm{NaOH}$ was added. The probe solution was removed after 16 hrs of hybridization at $65^{\circ} \mathrm{C}$ and the membrane was washed twice in $2 \times \mathrm{SSC}$ and $0.1 \% \mathrm{SDS}$ for $10 \mathrm{~min}$ at room temperature followed by two high stringency washes using $0.2 \times \mathrm{SSC}$ and $0.1 \% \mathrm{SDS}$ at $65^{\circ} \mathrm{C}$ for $10 \mathrm{~min}$, and exposure to a phosphor screen for $30 \mathrm{~min}$. The images were captured in Molecular Imager FX (BioRad). The hybridization intensity was measured in the captured images by densitometry analysis of the signal on individual clones using VisionWorksLS image acquisition and analysis software (UVP, USA). The relative abundance ratio of gene expression was calculated using the following formulas.

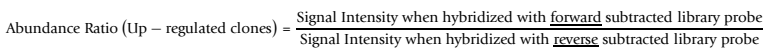

Abundance Ratio (down - regulated clones) $=\frac{\text { Signal Intensity when hybridized with reverse subtracted library probe }}{\text { Signal Intensity when hybridized with forward subtracted library probe }}$

All genes with an abundance ratio of more than one, a cut-off fixed arbitrarily, were then short-listed as the ones with true differential expression. These clones were subjected to automated DNA sequencing in an ABI Prism 310 sequencer (Applied Biosystems) with the Big Dye Terminator 3.0 kit (ABI Prism; Applied Biosystems) as per the manufacturer's directions using the primers TvectF and TvectR (Additional File 1, Table 1). The sequences thus obtained were analyzed using the BLAST online software (NCBI).

Three genes, randomly selected from the top five genes in Table 1 and 2 (with high abundance); one gene from the bottom (with lower abundance) of the table; and one gene, which was not short-listed, were used for real-time PCR analysis for validation of the short-listing procedure. Specific primers for these 10 genes (five from each of the up-regulated and down-regulated library) and primers for the house keeping gene GAPDH were designed (Additional File 1, Table 1) and used in the real-time PCR. cDNA was synthesized using 
Table 1 List of cDNAs up-regulated during PDH infection with DHBV

\begin{tabular}{|c|c|c|c|c|c|c|c|}
\hline No. & $\begin{array}{l}\text { Name of the } \\
\text { clone }\end{array}$ & $\begin{array}{l}\text { Abundance } \\
\text { Ratio }\end{array}$ & BLAST Result & $\begin{array}{l}\text { BLAST/ } \\
\text { tBLASTx }\end{array}$ & $\begin{array}{l}\text { Amplicon Size } \\
\text { (bp) }\end{array}$ & e-value & $\begin{array}{c}\text { GenBank Accession } \\
\text { No. }\end{array}$ \\
\hline 1 & F22 & 2.41 & $\begin{array}{l}\text { Cadherin 11, type 2, OB- } \\
\text { cadherin (osteoblast) } \\
\text { (CDH11)-Gallus gallus }\end{array}$ & BLAST & 462 & 0 & JG662697 \\
\hline 2 & F125 & 2.23 & $\begin{array}{c}\text { Pyruvate dehydrogenase E1- } \\
\text { beta subunit variant 3-like- } \\
\text { Taeniopygia guttata }\end{array}$ & BLAST & 268 & $2.00 \mathrm{E}-85$ & JG662698 \\
\hline 3 & F106 & 2.08 & $\begin{array}{c}\text { Anas platyrhynchos female- } \\
\text { specific sequence }\end{array}$ & tBLASTx & 371 & 3.00E-04 & JG662699 \\
\hline 4 & F8 & 2.04 & $\begin{array}{c}\text { Similar to SH3 domain } \\
\text { containing } 19-\text { Taeniopygia } \\
\text { guttata }\end{array}$ & tBLASTx & 678 & 4.00E-07 & JG662700 \\
\hline 5 & F71 & 2 & $\begin{array}{c}\text { Ubiquitin-like, containing } \\
\text { PHD and RING finger } \\
\text { domains, } 1 \text { (UHRF1)-Gallus } \\
\text { gallus }\end{array}$ & BLAST & 593 & 0 & JG662701 \\
\hline 6 & F21 & 1.87 & $\begin{array}{c}\text { Zinc finger CCCH-type } \\
\text { containing } 13 \text { (ZC3H13)- } \\
\text { Gallus gallus }\end{array}$ & BLAST & 681 & 0 & JG662702 \\
\hline 7 & F13 & 1.77 & $\begin{array}{l}\text { Succinate-CoA ligase, GDP- } \\
\text { forming, alpha subunit } \\
\text { (SUCLG1)-Gallus gallus }\end{array}$ & BLAST & 767 & 0 & JG662703 \\
\hline 8 & F76 & 1.76 & $\begin{array}{l}\text { ElaC homolog } 2 \text { (E. coli) } \\
\text { (ELAC2)-Gallus gallus }\end{array}$ & tBLASTx & 218 & $1.00 \mathrm{E}-14$ & JG662704 \\
\hline 9 & F19 & 1.58 & $\begin{array}{l}\text { CWC22 spliceosome- } \\
\text { associated protein homolog- } \\
\text { Taeniopygia guttata }\end{array}$ & BLAST & 680 & 0 & JG662705 \\
\hline 10 & F70 & 1.55 & $\begin{array}{c}\text { Similar to KIAA2019 protein/ } \\
\text { AHNAK nucleoprotein 2- } \\
\text { Gallus gallus }\end{array}$ & BLAST & 544 & $\begin{array}{l}1.00 \mathrm{E}- \\
150\end{array}$ & JG662706 \\
\hline 11 & F46 & 1.51 & Filamin B, beta-Gallus gallus & BLAST & 655 & $\begin{array}{l}1.00 \mathrm{E}- \\
140\end{array}$ & $J G 662707$ \\
\hline 12 & F77 & 1.45 & $\begin{array}{c}\text { Tumor necrosis factor } \\
\text { receptor superfamily,member } \\
\text { 6b, decoy (TNFRSF6B)-Gallus } \\
\text { gallus }\end{array}$ & tBLASTx & 527 & $5.00 \mathrm{E}-07$ & JG662708 \\
\hline 13 & F131 & 1.44 & $\begin{array}{l}\text { Nuclear protein Matrin } 3 \\
\text { (MATR3)-Gallus gallus }\end{array}$ & BLAST & 448 & 0 & JG662709 \\
\hline 14 & F45 & 1.42 & $\begin{array}{l}\text { Heat shock transcription } \\
\text { factor } 2 \text { (HSF2)-Gallus gallus }\end{array}$ & BLAST & 755 & 0 & JG662710 \\
\hline 15 & F74 & 1.42 & $\begin{array}{l}\text { High mobility group AT-hook } \\
2 \text { (HMGA2)-Gallus gallus }\end{array}$ & BLAST & 209 & $2.00 \mathrm{E}-49$ & $J G 662711$ \\
\hline 16 & F6 & 1.4 & CLE7-Gallus gallus & BLAST & 541 & 0 & $J G 662712$ \\
\hline 17 & F16 & 1.35 & $\begin{array}{c}\text { Cu/Zn superoxide dismutase } \\
\text { (SOD1)-Melopsittacus } \\
\text { undulatus }\end{array}$ & BLAST & 346 & $8.00 \mathrm{E}-31$ & $J G 662713$ \\
\hline 18 & F43 & 1.33 & $\begin{array}{l}\text { Exonuclease NEF-sp-Gallus } \\
\text { gallus }\end{array}$ & BLAST & 680 & $\begin{array}{l}9.00 \mathrm{E}- \\
143\end{array}$ & JG662714 \\
\hline 19 & F26 & 1.32 & $\begin{array}{c}\text { Component of oligomeric } \\
\text { golgi complex } 3 \text { (COG3)-Bos } \\
\text { taurus }\end{array}$ & tBLASTx & 308 & 0.002 & JG662715 \\
\hline 20 & $\mathrm{~F} 42$ & 1.31 & $\begin{array}{l}\text { CD9 protein-Anas } \\
\text { platyrhynchos }\end{array}$ & BLAST & 748 & 0 & $J G 662716$ \\
\hline 21 & F127 & 1.31 & $\begin{array}{l}\text { Junco hyemalis } 164 \text { gene, } \\
\text { partial sequence }\end{array}$ & tBLASTx & 234 & $5.00 \mathrm{E}-16$ & JG662717 \\
\hline 22 & F17 & 1.29 & $\begin{array}{c}\text { Quaking homolog, } \mathrm{KH} \\
\text { domain-Taeniopygia guttata }\end{array}$ & BLAST & 678 & 0 & JG662718 \\
\hline 23 & F44 & 1.29 & $\begin{array}{c}\text { Alanine-glyoxylate } \\
\text { aminotransferase 2-Gallus } \\
\text { gallus }\end{array}$ & tBLASTx & 721 & $5.00 \mathrm{E}-21$ & JG662719 \\
\hline
\end{tabular}


Table 1 List of cDNAs up-regulated during PDH infection with DHBV (Continued)

\begin{tabular}{|c|c|c|c|c|c|c|c|}
\hline 24 & F135 & 1.27 & $\begin{array}{l}\text { Leucine-rich repeats and } \\
\text { calponin homology }(\mathrm{CH}) \\
\text { domain containing 4- } \\
\text { Oryctolagus cuniculus }\end{array}$ & tBLASTx & 288 & 0.4 & JG662720 \\
\hline 25 & F14 & 1.24 & $\begin{array}{c}\text { Clathrin, light chain A (CLTA)- } \\
\text { Gallus gallus }\end{array}$ & BLAST & 673 & 0 & JG662721 \\
\hline 26 & F83 & 1.2 & Sequestosome 1-Gallus gallus & BLAST & 562 & 0 & JG662722 \\
\hline 27 & F10 & 1.18 & $\begin{array}{l}\text { RAB 32, member of Ras } \\
\text { oncogene-Gallus gallus }\end{array}$ & BLAST & 743 & 0 & JG662723 \\
\hline 28 & F30 & 1.16 & $\begin{array}{c}\text { Ribosomal protein L6 (RPL6)- } \\
\text { Gallus gallus }\end{array}$ & BLAST & 591 & 0 & JG662724 \\
\hline 29 & F64 & 1.16 & $\begin{array}{c}\text { Holocytochrome c synthase } \\
\text { (cytochrome c heme-lyase)- } \\
\text { Gallus gallus }\end{array}$ & tBLASTx & 421 & $8.00 \mathrm{E}-52$ & JG662725 \\
\hline 30 & F32 & 1.16 & $\begin{array}{l}\text { Lysosomal-associated } \\
\text { membrane protein 1- } \\
\text { Taeniopygia guttata }\end{array}$ & tBLASTx & 591 & 4.00E-93 & JG662726 \\
\hline 31 & F7 & 1.14 & $\begin{array}{l}\text { Serine protease } 23-\text { Gallus } \\
\text { gallus }\end{array}$ & BLAST & 740 & $\begin{array}{l}3.00 \mathrm{E}- \\
168\end{array}$ & JG662727 \\
\hline 32 & F18 & 1.09 & $\begin{array}{l}\text { Beta-catenin isolate 3-Anas } \\
\text { platyrhynchos }\end{array}$ & BLAST & 710 & 0 & JG662728 \\
\hline 33 & F52 & 1.09 & $\begin{array}{c}\text { Zebrafish DNA sequence } \\
\text { from clone } \mathrm{CH} 211-276 \mathrm{C} 22 \text { in } \\
\text { linkage group } 6\end{array}$ & tBLASTx & 218 & 2.2 & JG662729 \\
\hline 34 & F25 & 1.08 & $\begin{array}{l}\text { Gallus gallus finished cDNA, } \\
\text { clone ChEST457d18 }\end{array}$ & tBLASTx & 696 & $2.00 \mathrm{E}-27$ & JG662730 \\
\hline 35 & F59 & 1.07 & $\begin{array}{l}\text { Leucine proline-enriched } \\
\text { proteoglycan (leprecan)1/ } \\
\text { prolyl 3-hydroxylase } 1 \\
\text { (P3H1)-Gallus gallus }\end{array}$ & BLAST & 581 & 0 & JG662731 \\
\hline 36 & $\mathrm{~F} 12$ & 1.07 & Ribophorin I-Gallus gallus & BLAST & 796 & 0 & JG662732 \\
\hline 37 & F87 & 1.06 & $\begin{array}{l}\text { Gallus gallus finished cDNA, } \\
\text { clone ChEST855m19 }\end{array}$ & BLAST & 505 & $3.00 \mathrm{E}-91$ & JG662733 \\
\hline 38 & F95 & 1.06 & $\begin{array}{c}\text { Spastic paraplegia 3A } \\
\text { (autosomal dominant)-Gallus } \\
\text { gallus }\end{array}$ & BLAST & 316 & $3.00 \mathrm{E}-54$ & JG662734 \\
\hline 39 & F107 & 1.06 & $\begin{array}{l}\text { High-mobility group box 3- } \\
\text { Taeniopygia guttata }\end{array}$ & BLAST & 276 & $\begin{array}{l}2.00 \mathrm{E}- \\
136\end{array}$ & JG662735 \\
\hline 40 & F1 & 1.05 & $\begin{array}{l}\text { ATP synthase, } \mathrm{H}+ \\
\text { transporting, mitochondrial } \\
\text { F0 complex, subunit F2 } \\
\text { (ATP5J2)-Gallus gallus }\end{array}$ & tBLASTx & 199 & $9.00 \mathrm{E}-18$ & JG662736 \\
\hline 41 & F78 & 1.03 & $\begin{array}{l}\text { Ubiquitin specific peptidase } \\
47 \text { (USP47)-Gallus gallus }\end{array}$ & BLAST & 695 & 0 & JG662737 \\
\hline 42 & F88 & 1.03 & $\begin{array}{l}\text { No significant similarity } \\
\text { found }\end{array}$ & tBLASTx & 360 & - & JG662738 \\
\hline
\end{tabular}

total RNA from fresh sets of primary duck hepatocyte cultures either infected with DHBV or uninfected, as described above, using Avian Myeloblastosis Virus (AMV) reverse transcription system (Promega). Realtime PCR was carried out as previously described [12]. The experiments were repeated thrice, each in duplicates, and average fold change in gene expression was calculated for individual genes.

The threshold cycle $\left(C_{t}\right)$ values obtained in the realtime PCR analysis were normalized with the expression of the house-keeping gene GAPDH, and the relative expression of individual genes in infected and uninfected cells were calculated by Pfaffl method [13] for Day 0 and Day 4 of infection using the equation:

$$
\text { Ratio }=\frac{\left(\mathrm{E}_{\text {target }}\right)^{\left.\Delta \mathrm{C}_{\mathrm{T}} \text {,target(calibrator-test }\right)}}{\left(\mathrm{E}_{\mathrm{ref}}\right)^{\left.\Delta \mathrm{C}_{\mathrm{T}} \text {,ref(calibrator-test }\right)}}
$$

The ratios for day 0 and day 4 infected samples were compared and analysed statistically by paired Student's $\mathrm{t}$-test to validate the significance of gene expression changes. P-values $<0.05$ were considered significant. 
Table 2 List of CDNAs down-regulated during PDH infection with DHBV

\begin{tabular}{|c|c|c|c|c|c|c|c|}
\hline No. & Name of the clone & Abundance Ratio & BLAST Result & $\begin{array}{l}\text { BLAST/ } \\
\text { tBLASTx }\end{array}$ & Amplicon Size (bp) & e-value & GenBank Accession No. \\
\hline 1 & R73 & 1.52 & $\begin{array}{l}\text { Ferritin, heavy polypeptide } 1 \\
\text { (FTH1)-Gallus gallus }\end{array}$ & BLAST & 342 & $4.00 \mathrm{E}-143$ & JG662661 \\
\hline 2 & R90 & 1.41 & $\begin{array}{c}\text { Zinc finger CCCH-type, } \\
\text { antiviral } 1 \text { ( }(\text { CC3HAV1)-Gallus } \\
\text { gallus }\end{array}$ & tBLASTx & 328 & $1.00 \mathrm{E}-14$ & JG662662 \\
\hline 3 & R130 & 1.39 & $\begin{array}{l}\text { T-complex 1-Taeniopygia } \\
\text { guttata }\end{array}$ & BLAST & 400 & $6.00 \mathrm{E}-172$ & JG662663 \\
\hline 4 & R108 & 1.39 & $\begin{array}{l}\text { Y box binding protein 1- } \\
\text { Gallus gallus }\end{array}$ & BLAST & 486 & 0 & JG662664 \\
\hline 5 & R96 & 1.34 & $\begin{array}{l}\text { MYST/Esa1-associated factor } \\
\text { 6-Taeniopygia guttata }\end{array}$ & BLAST & 646 & $1.00 \mathrm{E}-17$ & JG662665 \\
\hline 6 & R97 & 1.33 & $\begin{array}{c}\text { Similar to RGD-CAP-Gallus } \\
\text { gallus }\end{array}$ & BLAST & 743 & 0 & JG662666 \\
\hline 7 & R111 & 1.31 & $\begin{array}{l}\text { PREDICTED: Gallus gallus } \\
\text { similar to Ankycorbin }\end{array}$ & BLAST & 646 & 0 & JG662667 \\
\hline 8 & R134 & 1.3 & $\begin{array}{l}\text { No significant similarity } \\
\text { found }\end{array}$ & tBLASTx & 490 & - & JG662668 \\
\hline 9 & R123 & 1.25 & $\begin{array}{l}\text { ATPase8, ATPase6 genes for } \\
\text { F0-ATP synthase subunit 8, } \\
\text { F0-ATP synthase subunit 6- } \\
\text { Anas platyrhynchos }\end{array}$ & BLAST & 462 & 0 & $J G 662669$ \\
\hline 10 & R133 & 1.24 & Versican-Gallus gallus & BLAST & 257 & $3.00 \mathrm{E}-98$ & $J G 662670$ \\
\hline 11 & R103 & 1.22 & $\begin{array}{l}\text { Platelet-activating factor } \\
\text { acetylhydrolase isoform lb, } \\
\text { alpha subunit } 45 \mathrm{kDa} \\
\text { (PAFAH1B1)-Gallus gallus }\end{array}$ & BLAST & 508 & $4.00 \mathrm{E}-145$ & JG662671 \\
\hline 12 & R16 & 1.18 & UPF0308 protein-Gallus gallus & BLAST & 593 & 0 & JG662672 \\
\hline 13 & R100 & 1.17 & $\begin{array}{l}\text { TRAF interacting protein } \\
\text { (TRAIP)-Gallus gallus }\end{array}$ & BLAST & 631 & 0 & JG662673 \\
\hline 14 & R84 & 1.16 & $\begin{array}{c}\text { Acid alpha-glucosidase- } \\
\text { Macaca mulatta }\end{array}$ & tBLASTx & 756 & 3.8 & JG662674 \\
\hline 15 & R15 & 1.15 & $\begin{array}{c}\text { Microtubule-associated } \\
\text { protein RP/EB family, } \\
\text { member 1-Taeniopygia } \\
\text { guttata }\end{array}$ & BLAST & 438 & $5.00 \mathrm{E}-168$ & JG662675 \\
\hline 16 & R126 & 1.15 & $\begin{array}{l}\text { Catechol-O- } \\
\text { methyltransferase-Gallus } \\
\text { gallus }\end{array}$ & tBLASTx & 395 & $1.00 \mathrm{E}-25$ & $J G 662676$ \\
\hline 17 & R135 & 1.14 & $\begin{array}{c}\text { Chromosome } 15 \text { hypothetical } \\
\text { ATG/GTP binding protein- } \\
\text { Gallus gallus }\end{array}$ & tBLASTx & 239 & 0.048 & JG662677 \\
\hline 18 & R143 & 1.13 & $\begin{array}{l}\text { Ankyrin repeat domain } 17 \\
\text { (ANKRD17)-Gallus gallus }\end{array}$ & BLAST & 546 & 0 & $J G 662678$ \\
\hline 19 & R45 & 1.13 & $\begin{array}{c}\text { Splicing factor, arginine/ } \\
\text { serine-rich } 18 \text { (SFRS18)-Gallus } \\
\text { gallus }\end{array}$ & tBLASTx & 476 & $1.00 \mathrm{E}-145$ & JG662679 \\
\hline 20 & R141 & 1.11 & $\begin{array}{l}\text { Cytochrome oxidase subunit } \\
\text { I (COI)-Anas platyrhynchos }\end{array}$ & BLAST & 336 & 1.00E-152 & JG662680 \\
\hline 21 & R10 & 1.11 & $\begin{array}{c}\text { Eukaryotic translation } \\
\text { initiation factor } 5 \text { (EIF5)-Gallus } \\
\text { gallus }\end{array}$ & BLAST & 735 & 0 & $J G 662681$ \\
\hline 22 & R129 & 1.11 & $\begin{array}{l}\text { Beta-actin-Anas } \\
\text { platyrhynchos }\end{array}$ & BLAST & 664 & 0 & $J G 662682$ \\
\hline 23 & R106 & 1.1 & Alpha enolase-Peking Duck & BLAST & 381 & 0 & $J G 662683$ \\
\hline 24 & R93 & 1.1 & $\begin{array}{l}\text { No significant similarity } \\
\text { found }\end{array}$ & tBLASTx & 488 & - & JG662684 \\
\hline 25 & R139 & 1.1 & $\begin{array}{l}\text { Similar to KIAA1824 protein/ } \\
\text { WD repeat domain 22-Gallus } \\
\text { gallus }\end{array}$ & BLAST & 279 & 7.00E-100 & $J G 662685$ \\
\hline
\end{tabular}


Table 2 List of cDNAs down-regulated during PDH infection with DHBV (Continued)

\begin{tabular}{|c|c|c|c|c|c|c|c|}
\hline 26 & R104 & 1.09 & $\begin{array}{c}\text { Caspase 3, apoptosis-related } \\
\text { cysteine peptidase (CASP3)- } \\
\text { Gallus gallus }\end{array}$ & BLAST & 792 & 0 & JG662686 \\
\hline 27 & R95 & 1.09 & $\begin{array}{l}\text { Gallus gallus finished cDNA, } \\
\text { clone ChEST757h13 }\end{array}$ & tBLASTx & 793 & $5.00 \mathrm{E}-19$ & JG662687 \\
\hline 28 & R79 & 1.07 & $\begin{array}{l}\text { Ral guanine nucleotide } \\
\text { dissociation stimulator-like } 1 \\
\text { (RGL1)-Gallus gallus }\end{array}$ & BLAST & 333 & $1.00 \mathrm{E}-132$ & JG662688 \\
\hline 29 & R105 & 1.06 & $\begin{array}{l}\text { Gallus gallus similar to } \\
\text { MGC53471 protein }\end{array}$ & BLAST & 646 & 7.00E-89 & JG662689 \\
\hline 30 & $\mathrm{R} 128$ & 1.05 & $\begin{array}{c}\text { Hydroxyacyl glutathione } \\
\text { hydrolase-like,transcript } \\
\text { variant 2-Taeniopygia guttata }\end{array}$ & BLAST & 382 & $4.00 \mathrm{E}-54$ & JG662690 \\
\hline 31 & $\mathrm{R} 22$ & 1.05 & $\begin{array}{c}\text { Proteasome (prosome, } \\
\text { macropain) } 265 \text { subunit, } \\
\text { ATPase,1 (PSMC1)-Gallus } \\
\text { gallus }\end{array}$ & BLAST & 324 & 4.00E-133 & JG662691 \\
\hline 32 & R99 & 1.04 & $\begin{array}{c}\text { Gallus gallus hypothetical } \\
\text { protein }\end{array}$ & BLAST & 362 & $2.00 \mathrm{E}-86$ & JG662692 \\
\hline 33 & R2 & 1.04 & $\begin{array}{l}\text { Ribosomal protein L35a- } \\
\text { Gallus gallus }\end{array}$ & BLAST & 90 & $3.00 \mathrm{E}-08$ & JG662693 \\
\hline 34 & R36 & 1.04 & $\begin{array}{l}\text { Gallus gallus finished cDNA, } \\
\text { clone ChEST191i5 }\end{array}$ & tBLASTx & 414 & 0.025 & JG662694 \\
\hline 35 & R124 & 1.02 & $\begin{array}{l}\text { Gallus gallus BAC clone } \\
\text { CH261-189F16 from } \\
\text { chromosome z }\end{array}$ & BLAST & 524 & 0 & JG662695 \\
\hline 36 & R86 & 1.02 & $\begin{array}{c}\text { Transmembrane protein 30A- } \\
\text { Taeniopygia guttata }\end{array}$ & BLAST & 220 & 4.00E-72 & JG662696 \\
\hline
\end{tabular}

\section{Results \& Discussion}

The infection of PDH with DHBV did not produce any visible changes on the cell monolayer (Figure 1A). The virus infection was confirmed by PCR detection of a $300 \mathrm{bp}$ DHBV glycoprotein 1 (gp1) gene fragment in the DNA isolated from infected PDH culture supernatant (Figure 1B) and by sequence analysis. The establishment of a productive infection was indicated by the increasing PCR amplification intensity of the gene fragment with every successive day of culture for the total culture period of eight days. For RNA isolation for subtraction library construction, we selected an early time point of 4 days as described in previous studies [14]. Two libraries were generated- the forward subtracted or up-regulated genes and the reverse subtracted or down-regulated genes. The efficiency of subtraction procedure was indicated by a decrease in the intensity and appearance of discrete banding patterns in the lanes with subtracted products (Figure 1C) and was confirmed by PCR detection of the house-keeping gene GAPDH, the amplicons of which appeared at an earlier time point ( 25 cycles) in un-subtracted samples compared to a later time point (30 cycles) in both forward and reverse subtracted libraries (Figure 1D). Hybridization of macroarrays blotted with 137 up-regulated and 148 down-regulated clones (Figure 1E) and short-listing only the ones with an abundance ratio of more than 1 , we obtained 42 nonredundant up-regulated clones and 36 non-redundant down-regulated clones (Tables 1 and 2). Real-time PCR done using the representative sets of short-listed clones gave results confirming the reliability of the short-listing procedure. Genes that topped the differential expression among the up-regulated genes (F22, F8, F71) showed a significant $(\mathrm{P}<0.05)$ increase in expression at 4 -days compared to the 0 day in infected PDH (Figure 2A), while the reverse was the case of the down-regulated genes (R73, R90, R130) (Figure 2B), all of whose expression decreased significantly $(\mathrm{P}<0.05)$ at 4 -day DHBV infection. F88 and R86, which were selected from the bottom end of the up-regulated and down-regulated gene-tables, respectively, also showed the expected modulation albeit at a lower fold. F62 and R47, picked from the genes left-out did not show any significant difference in their expression pattern.

Functional classification of the short-listed clones using gene ontology based on BLAST results grouped them mainly into those belonging to cellular processes such as cellular respiration, signal transduction, transcription/translation, ubiquitin/proteasome pathway and apoptosis besides those coding for membrane and cytoskeletal proteins (Table 3). Among them, the category that was maximum up-regulated were the ones involved 


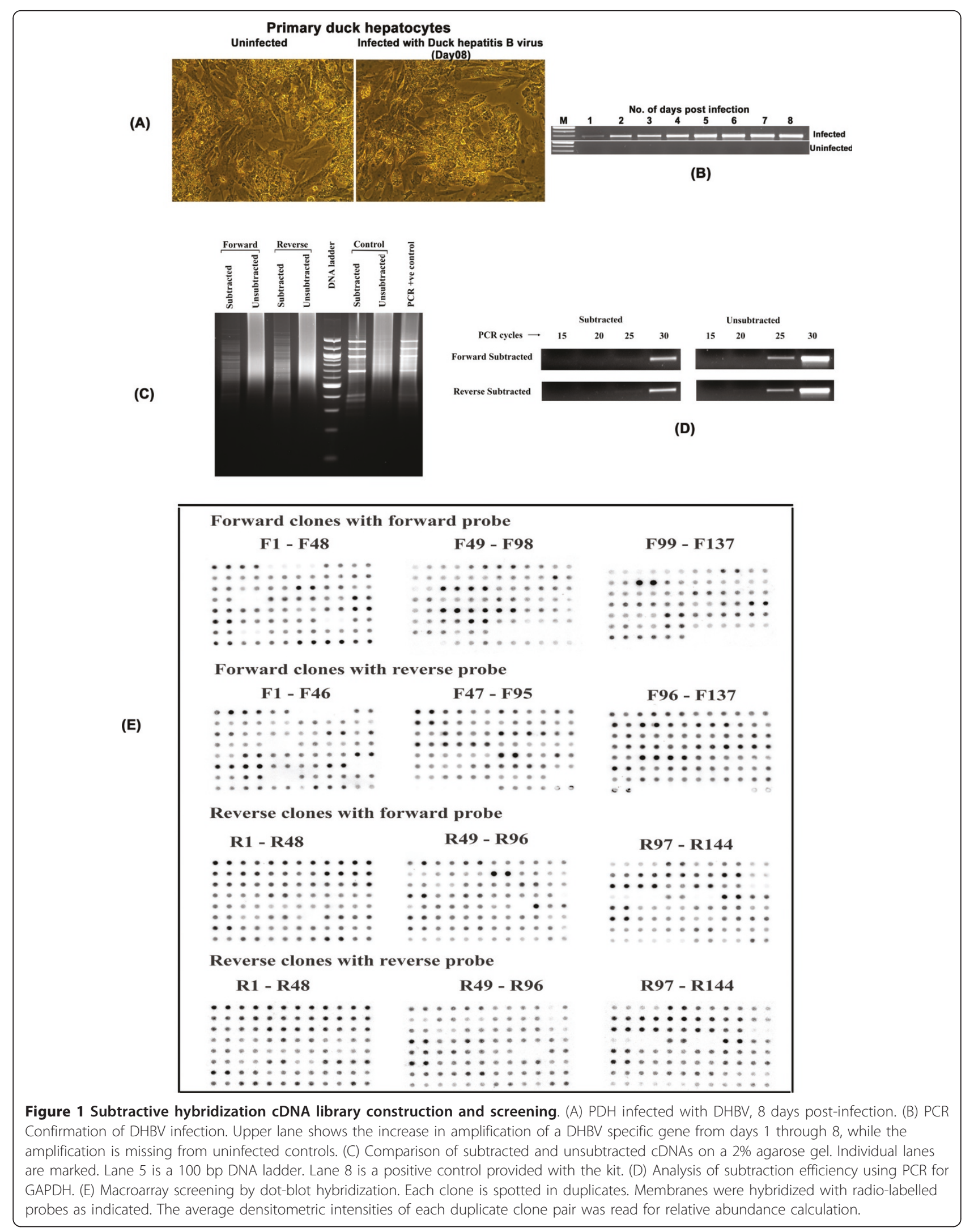




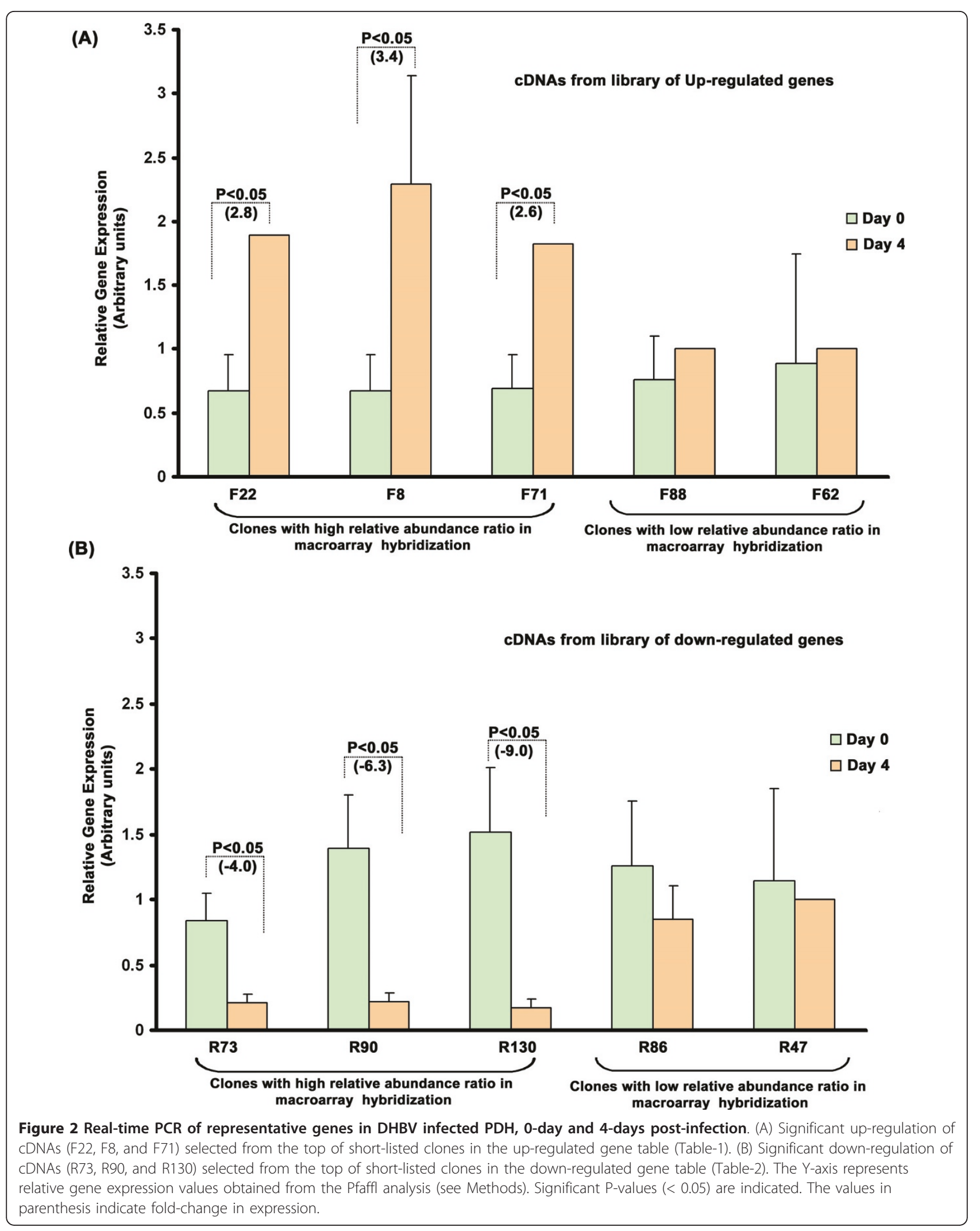


Table 3 Categorization of genes according to the reported function available from literature

\begin{tabular}{|c|c|c|}
\hline & FORWARD & REVERSE \\
\hline \multirow[t]{4}{*}{ Membrane proteins } & Cadherin 11 & Transmembrane protein 30A \\
\hline & Lysosomal-associated membrane protein 1 & \\
\hline & CD9 protein & \\
\hline & $\begin{array}{l}\text { Leucine-rich repeats and calponin homology }(\mathrm{CH}) \text { domain } \\
\text { containing } 4\end{array}$ & \\
\hline \multirow[t]{4}{*}{ Cellular Respiration } & Pyruvate dehydrogenase E1-beta subunit & Alpha enolase \\
\hline & Succinate-CoA ligase, GDP-forming, alpha subunit(SUCLG1) & Hydroxyacyl glutathione hydrolase-like \\
\hline & $\begin{array}{c}\text { ATP synthase, } \mathrm{H}+\text { transporting, mitochondrial F0 complex, } \\
\text { subunit F2(ATP5J2) }\end{array}$ & $\begin{array}{c}\text { ATPase8, ATPase6 genes for F0-ATP synthase subunit 8, F0-ATP } \\
\text { synthase subunit } 6\end{array}$ \\
\hline & & Cytochrome oxidase subunit I (COI) \\
\hline \multirow[t]{4}{*}{ Cytoskeletal } & Filamin B, beta & Beta-actin \\
\hline & & T-complex 1 \\
\hline & & Microtubule-associated protein RP/EB family, member 1 \\
\hline & & Similar to Ankycorbin \\
\hline \multirow[t]{2}{*}{ Signal Transduction } & Beta-catenin isolate 3 & TRAF interacting protein (TRAIP) \\
\hline & Quaking homolog, KH domain & \\
\hline \multirow{8}{*}{$\begin{array}{l}\text { Transcription and } \\
\text { Translation }\end{array}$} & High mobility group AT-hook 2 (HMGA2) & Splicing factor, arginine/serine-rich 18 (SFRS18) \\
\hline & High-mobility group box 3 & MYST/Esa1-associated factor 6 \\
\hline & Heat shock transcription factor 2 (HSF2) & Y box binding protein 1 \\
\hline & CWC22 spliceosome-associated protein homolog & Ribosomal protein L35a \\
\hline & $\begin{array}{l}\text { Ubiquitin-like, containing PHD and RING finger domains, } 1 \\
\text { (UHRF1) }\end{array}$ & Eukaryotic translation initiation factor 5 (EIF5) \\
\hline & Nuclear protein Matrin 3 (MATR3) & \\
\hline & Ribosomal protein L6 (RPL6) & \\
\hline & Ribophorin I & \\
\hline \multirow[t]{2}{*}{$\begin{array}{l}\text { Ubiquitin- } \\
\text { proteasome }\end{array}$} & Ubiquitin specific peptidase 47 (USP47) & $\begin{array}{l}\text { Proteasome (prosome, macropain) } 26 \mathrm{~S} \text { subunit, ATPase, } 1 \\
\text { (PSMC1) }\end{array}$ \\
\hline & Sequestosome 1 & \\
\hline Apoptosis & $\begin{array}{l}\text { Tumor necrosis factor receptor superfamily, member 6b, } \\
\text { decoy (TNFRSF6B) }\end{array}$ & Caspase 3, apoptosis-related cysteine peptidase (CASP3) \\
\hline \multirow[t]{21}{*}{ Others } & Anas platyrhynchos female-specific sequence & No significant similarity found \\
\hline & Junco hyemalis 164 gene, partial sequence & UPF0308 protein \\
\hline & Gallus gallus finished cDNA, clone ChEST457d18 & No significant similarity found \\
\hline & No significant similarity found & Gallus gallus finished cDNA, clone ChEST757h13 \\
\hline & Gallus gallus finished cDNA, clone ChEST855m19 & Gallus gallus finished cDNA, clone ChEST191i5 \\
\hline & $\begin{array}{c}\text { Zebrafish DNA sequence from clone } \mathrm{CH} 211-276 \mathrm{C} 22 \text { in } \\
\text { linkage group } 6\end{array}$ & Gallus gallus BAC clone $\mathrm{CH} 261-189 \mathrm{~F} 16$ from chromosome z \\
\hline & Similar to SH3 domain containing 19 & Gallus gallus hypothetical protein \\
\hline & Zinc finger CCCH-type containing 13 (ZC3H13) & Gallus gallus similar to MGC53471 protein \\
\hline & ElaC homolog 2 (E. coli) (ELAC2) & Ferritin, heavy polypeptide 1 (FTH1) \\
\hline & Similar to KIAA2019 protein/AHNAK nucleoprotein 2 & Zinc finger CCCH-type, antiviral 1 (ZC3HAV1) \\
\hline & CLE7 & Similar to RGD-CAP \\
\hline & Cu/Zn superoxide dismutase (SOD1) & Versican \\
\hline & Exonuclease NEF-sp & $\begin{array}{l}\text { Platelet-activating factor acetylhydrolase isoform Ib, alpha } \\
\text { subunit 45kDa (PAFAH1B1) }\end{array}$ \\
\hline & Component of oligomeric golgi complex 3 (COG3) & Catechol-O-methyltransferase \\
\hline & Clathrin, light chain A (CLTA) & Chromosome 15 hypothetical ATG/GTP binding protein \\
\hline & RAB 32, member of Ras oncogene & Ankyrin repeat domain 17 (ANKRD17) \\
\hline & Holocytochrome c synthase (cytochrome c heme-lyase) & Similar to KIAA1824 protein/WD repeat domain 22 \\
\hline & Serine protease 23 & Ral guanine nucleotide dissociation stimulator-like 1 (RGL1) \\
\hline & $\begin{array}{c}\text { Leucine proline-enriched proteoglycan (leprecan)1/prolyl 3- } \\
\text { hydroxylase } 1 \text { ( } \mathrm{P} 3 \mathrm{H} 1)\end{array}$ & Acid alpha-glucosidase \\
\hline & Spastic paraplegia 3A (autosomal dominant) & \\
\hline & Alanine-glyoxylate aminotransferase 2 & \\
\hline
\end{tabular}


in transcription/translation (19\%), whereas the ones maximum down regulated (11\%) belonged to cytoskeletal proteins. The former included the HMG Box proteins and Y-box binding proteins. Previous studies have implicated the Y-box binding protein1, Platelet-activating factor acetylhydrolase isoform 1B (PAFAH1B1), Ribosomal Protein L35a, Ferritin, $\alpha$-enolase, Caspase 3, CuZn Superoxide Dismutase (CuZnSOD), Filamin B, Pyruvate dehydrogenase $1-\beta, \beta$-catenin, prolyl-3-hydroxylase $1, \beta$-actin, acid $\alpha$-glucosidase, and clathrin, the cDNAs of which were identified to be up-regulated, with chronic HBV infections and HCC development [6,15-26]. In comparison to the earlier report based on proteome analysis in DHBV infected PDH [8], except for $\beta$-actin and $\alpha$-enolase, all the cDNAs identified in the present study represented new genes. The difference could be due to multiple reasons, and importantly it might include the selective enrichment/elimination of some of the cDNAs during the process of RT-PCR amplification and cloning as part of the subtraction library construction. Nevertheless, our data provides a new set of candidate genes worth further investigation in hepadnaviral infection.

An interesting observation in this study was the inverse pattern of differential expression of ten of these genes in in vitro DHBV infected cells as against the reports on HCC clinical samples [6,15-20]. The mRNAs for the Ybox binding protein1, PAFAH1B1, Ribosomal Protein L35a, Ferritin, $\alpha$-enolase, acid alpha-glucosidase and Caspase 3 were shown to be down-regulated during in vitro DHBV infection, whereas those of CuZnSOD, Filamin B and Pyruvate dehydrogenase were shown to be up-regulated, where as the reverse was the trend in human HCC. This observation may be purely coincidental owing to the fact that the experimental method we used was an in vitro system, and the changes in primary hapatocytes during culture itself, such as de-differentiation, might have led to these alterations in gene expression.

\section{Conclusions}

In summary, the present study identified cDNAs of a number of genes that are differentially modulated in cultured PDH, invitro infected with DHBV. cDNAs of both novel as well as already reported genes/proteins associated with HBV/DHBV infection or HCC were identified in the library. The genes short-listed here could be valuable leads for further studies in animal models, which might help to understand the pathology of chronic HBV infections and pathogenesis of HCC.

\section{Additional material}

Additional file 1: Primers used in the study.

\section{Acknowledgements}

The financial support by the Department of Biotechnology, Government of India (Grant No. BT/PR8930/GBD/27/39/2006) is gratefully acknowledged.

\section{Authors' contributions}

SN, DSA and Al carried out the experiments. SN drafted the manuscript. ES conceived the study, edited and completed the final version of the manuscript. All authors read and approved the final manuscript.

\section{Competing interests}

The authors declare that they have no competing interests.

Received: 1 April 2011 Accepted: 23 July 2011 Published: 23 July 2011

\section{References}

1. Funk A, Mhamdi M, Will H, Sirma H: Avian hepatitis B viruses: molecular and cellular biology, phylogenesis, and host tropism. World J Gastroenterol 2007, 13:91-103.

2. Gripon P, Rumin S, Urban S, Le Seyec J, Glaise D, Cannie I, Guyomard C, Lucas J, Trepo C, Guguen-Guillouzo C: Infection of a human hepatoma cell line by hepatitis B virus. Proc Natl Acad Sci USA 2002, 99:15655-15660.

3. Schultz U, Grgacic E, Nassal M: Duck hepatitis B virus: an invaluable model system for HBV infection. Adv Virus Res 2004, 63:1-70.

4. Ganem D, Schneider RJ: Hepadnaviridae: The viruses and their replication. In Fields Virology. Volume 2. 4 edition. Edited by: Knipe DM, Howley PM. Philadelphia: Lippincott, Williams and Wilkins; 2001:2923-2969.

5. Kao JH, Chen PJ, Chen DS: Recent advances in the research of hepatitis $B$ virus-related hepatocellular carcinoma: epidemiologic and molecular biological aspects. Adv Cancer Res 108:21-72.

6. Xu XR, Huang J, Xu ZG, Qian BZ, Zhu ZD, Yan Q, Cai T, Zhang X, Xiao HS, Qu J, Liu F, Huang QH, Cheng ZH, Li NG, Du JJ, Hu W, Shen KT, Lu G, Fu G, Zhong M, Xu SH, Gu WY, Huang W, Zhao XT, Hu GX, Gu JR, Chen Z, Han ZG: Insight into hepatocellular carcinogenesis at transcriptome level by comparing gene expression profiles of hepatocellular carcinoma with those of corresponding noncancerous liver. Proc Natl Acad Sci USA 2001, 98:15089-15094.

7. Bellodi-Privato M, Kubrusly MS, Stefano JT, Soares IC, Wakamatsu A, Oliveira AC, Alves VA, Bacchella T, Machado MC, D'Albuquerque LA: Differential gene expression profiles of hepatocellular carcinomas associated or not with viral infection. Braz J Med Biol Res 2009, 42:119-1127.

8. Zhao Y, Ben H, Qu S, Zhou X, Yan L, Xu B, Zhou S, Lou Q, Ye R, Zhou T, Yang P, Qu D: Proteomic analysis of primary duck hepatocytes infected with duck hepatitis B virus. Proteome Sci 8:28.

9. Tuttleman JS, Pugh JC, Summers JW: In vitro experimental infection of primary duck hepatocyte cultures with duck hepatitis B virus. J Virol 1986, 58:17-25.

10. Summers J, Smith PM, Huang MJ, Yu MS: Morphogenetic and regulatory effects of mutations in the envelope proteins of an avian hepadnavirus. J Virol 1991, 65:1310-1317.

11. Turin F, Borel C, Benchaib M, Kay A, Jamard C, Guguen-Guillouzo C, Trepo C, Hantz O: n-Butyrate, a cell cycle blocker, inhibits early amplification of duck hepatitis B virus covalently closed circular DNA after in vitro infection of duck hepatocytes. J Virol 1996, 70:2691-2696.

12. Arathy DS, Nair S, Soman SS, Issac A, Sreekumar E: Functional characterization of the CC chemokine RANTES from Pekin duck (Anas platyrhynchos). Dev Comp Immunol 35:142-150.

13. Pfaffl MW: A new mathematical model for relative quantification in realtime RT-PCR. Nucleic Acids Res 2001, 29:e45.

14. Qiao M, Scougall CA, Duszynski A, Burrell CJ: Kinetics of early molecular events in duck hepatitis B virus replication in primary duck hepatocytes. J Gen Virol 1999, 80(Pt 8):2127-2135.

15. Yasen M, Kajino K, Kano S, Tobita H, Yamamoto J, Uchiumi T, Kon S, Maeda M, Obulhasim G, Arii S, Hino O: The up-regulation of Y-box binding proteins (DNA binding protein A and Y-box binding protein-1) as prognostic markers of hepatocellular carcinoma. Clin Cancer Res 2005, 11:7354-7361.

16. Pan YS, Lee YS, Lee YL, Lee WC, Hsieh SY: Differentially profiling the lowexpression transcriptomes of human hepatoma using a novel $\mathrm{SSH} /$ microarray approach. BMC Genomics 2006, 7:131. 
17. Kim MY, Park E, Park JH, Park DH, Moon WS, Cho BH, Shin HS, Kim DG: Expression profile of nine novel genes differentially expressed in hepatitis B virus-associated hepatocellular carcinomas. Oncogene 2001, 20:4568-4575.

18. Blumberg BS, Lustbader ED, Whitford PL: Changes in serum iron levels due to infection with hepatitis B virus. Proc Natl Acad Sci USA 1981, 78:3222-3224

19. Takashima M, Kuramitsu Y, Yokoyama Y, lizuka N, Fujimoto M, Nishisaka T, Okita K, Oka M, Nakamura K: Overexpression of alpha enolase in hepatitis $C$ virus-related hepatocellular carcinoma: association with tumor progression as determined by proteomic analysis. Proteomics 2005, 5:1686-1692.

20. Chang CS, Huang SM, Lin HH, Wu CC, Wang CJ: Different expression of apoptotic proteins between HBV-infected and non-HBV-infected hepatocellular carcinoma. Hepatogastroenterology 2007, 54:2061-2068

21. Gottlob K, Fulco M, Levrero M, Graessmann A: The hepatitis B virus HBx protein inhibits caspase 3 activity. J Biol Chem 1998, 273:33347-33353.

22. Hung JH, Yan CW, Su IJ, Wang HC, Lei HY, Lin WC, Chang WT, Huang W, Lu TJ, Lai MD: Hepatitis B virus surface antigen interacts with acid alphaglucosidase and alters glycogen metabolism. Hepatol Res 40:633-640.

23. Elchuri S, Oberley TD, Qi W, Eisenstein RS, Jackson Roberts L, Van Remmen $H$, Epstein $C J$, Huang $T$ : CuZnSOD deficiency leads to persistent and widespread oxidative damage and hepatocarcinogenesis later in life. Oncogene 2005, 24:367-380.

24. Thompson MD, Monga SP: WNT/beta-catenin signaling in liver health and disease. Hepatology 2007, 45:1298-1305.

25. Zhai B, Yan HX, Liu SQ, Chen L, Wu MC, Wang HY: Reduced expression of E-cadherin/catenin complex in hepatocellular carcinomas. World J Gastroenterol 2008, 14:5665-5673.

26. Risteli J, Tuderman L, Tryggvason K, Kivirikko Kl: Effect of hepatic injury on prolyl 3-hydroxylase and 4-hydroxylase activities in rat liver and on immunoreactive prolyl 4-hydroxylase concentrations in the liver and serum. Biochem J 1978, 170:129-135.

doi:10.1186/1743-422X-8-363

Cite this article as: Nair et al.: Differential gene expression analysis of in vitro duck hepatitis B virus infected primary duck hepatocyte cultures. Virology Journal 2011 8:363.

\section{Submit your next manuscript to BioMed Central and take full advantage of:}

- Convenient online submission

- Thorough peer review

- No space constraints or color figure charges

- Immediate publication on acceptance

- Inclusion in PubMed, CAS, Scopus and Google Scholar

- Research which is freely available for redistribution

Submit your manuscript at www.biomedcentral.com/submit 